\title{
Acute gastroenteritis and video camera surveillance: a cruise ship case report
}

\author{
Arthur L. Diskin ${ }^{1}$, Gina M. Caro ${ }^{1}$, Eilif Dahl ${ }^{2}$ \\ ${ }^{1}$ Azamara Club Cruises, Celebrity Cruises, Royal Caribbean International, Medical and Public Health, Miami, Florida, USA \\ ${ }^{2}$ Department of Occupational Medicine, Haukeland University Hospital, Norwegian Centre for Maritime Medicine, Bergen, Norway
}

\begin{abstract}
A 'faecal accident' was discovered in front of a passenger cabin of a cruise ship. After proper cleaning of the area the passenger was approached, but denied having any gastrointestinal symptoms. However, when confronted with surveillance camera evidence, she admitted having the accident and even bringing the towel stained with diarrhoea back to the pool towels bin. She was isolated until the next port where she was disembarked.

Acute gastroenteritis (AGE) caused by Norovirus is very contagious and easily transmitted from person to person on cruise ships. The main purpose of isolation is to avoid public vomiting and faecal accidents. To quickly identify and isolate contagious passengers and crew and ensure their compliance are key elements in outbreak prevention and control, but this is difficult if ill persons deny symptoms. All passenger ships visiting US ports now have surveillance video cameras, which under certain circumstances can assist in finding potential index cases for AGE outbreaks.
\end{abstract}

(Int Marit Health 2014; 65, 1: 20-22)

Key words: acute gastroenteritis, isolation, security video camera surveillance, cruise medicine

\section{INTRODUCTION}

Acute gastroenteritis (AGE) caused by Norovirus is very contagious and easily transmitted from person to person on cruise ships. Identification of potentially contagious passengers and crew and ensuring their compliance with isolation protocols are key elements in outbreak prevention and control. We present a cruise ship case that highlights some of the challenges.

\section{CASE REPORT}

The ship's command center (Emergency \#911) was informed about a 'faecal accident' happening in a corridor in front of a passenger cabin and immediately activated the 'Public Vomit Incident' action plan used for vomiting and faecal incidents according to fleet-wide instructions. The Executive Housekeeper, the Assistant Executive Housekeeper and the state room attendant checked the area, contacted the passenger in the adjacent stateroom and asked her if she was feeling well or needed any medical assistance. The passenger denied any gastrointestinal symptoms. The area was promptly sanitised according to the protocol, including use of a hot steam fog machine.

The Executive Housekeeper called the Medical Facility and advised about the incident. The ship's doctor called the passenger and asked about her condition. She firmly denied any gastrointestinal symptoms and furthermore stated that she is a nurse and reassured the ship's medical staff that she knows how serious such matters are on ships.

The security personnel then checked the closed circuit television (CCTV) cameras. They found that this very same passenger was the only person in the contaminated area around the time when the incident happened and her entry to her stateroom occurred at the same time. She was also caught on camera going back to the pool area, although she had denied ever having been near the pool.

The Hotel Director, the Guest (Passenger) Services Manager and the Front Desk Manager were advised about the findings. The Front Desk Manager visited the cabin

Prof. Eilif Dahl, MD, MHA, PhD, Professor Dahls gate 50A, 0260 Oslo, Norway, tel: +47 95921 759, fax: +47 225631 12, e-mail: eilifdahl@hotmail.com 
and informed the passenger about the policies of isolation, showing sympathy and compassion for whatever gastrointestinal issue she suffered, but emphasising that reporting gastroenteritis symptoms is a must.

The passenger initially denied all allegations, but after she was presented with video evidence, she gave in and even admitted that she took the towel stained with diarrhea back to the pool towels bin. Subsequently, the passenger was kept isolated in her cabin under strict surveillance and was disembarked after isolation in the next port according to the Guest Conduct Policy.

There was no AGE outbreak on board that cruise.

\section{DISCUSSION}

Norovirus is now the most frequent cause of AGE outbreaks on cruise ships. In 20139 ships reported outbreaks to the US Centers for Disease Control and Prevention (CDC), and in 7 of them Norovirus was the causative agent [1]. AGE ruining cruise holidays always creates media storms and the companies are criticised for not doing enough to prevent and control outbreaks. CDC's Vessel Sanitation Program (VSP) was introduced in the early 1970s. It assists the cruise industry to prevent and control the introduction, transmission, and spread of gastrointestinal illnesses on cruise ships, which have a foreign itinerary with US ports [2]. Now many other countries have introduced similar programs for passenger vessels based on CDC's long-time cruise experience [3].

Health authorities define a 'reportable case' as:

- diarrhea (3 or more episodes of loose stools in a 24-h period); or

- vomiting and 1 additional symptom including 1 or more episodes of loose stools in a 24-h period, or abdominal cramps, or headache, or muscle aches, or fever (temperature of $\left.\geq 38^{\circ} \mathrm{C}\left[100.4^{\circ} \mathrm{F}\right]\right)$.

VSP recommends that reportable cases among passengers and crew should be isolated until symptom free for a minimum of $24 \mathrm{~h}$ (food employees: $48 \mathrm{~h}$ !) [4].

Isolation means that patients are not allowed to leave their cabins, can only communicate by phone and are not allowed to receive unauthorised visitors.

Case definitions are useful for statistics and policies, but for many conditions of public health importance action to contain disease should be initiated as soon as a problem is identified. Hence, reporting vomiting once (if not seasick) or one loose bowel movement will on most ships trigger immediate 'proactive isolation' - just in case.

Most cases of Norovirus are of short duration clinically. The main purpose of isolation is to avoid public vomiting and faecal accidents. The vomiting in Norovirus cases occurs rapidly with little or no warning, precluding the passenger or crew getting back to their staterooms.
A vomit or faecal accident occurring in a common public area can easily start an outbreak and rapid cleaning and containment is essential. Norovirus can survive on surfaces for extended periods. High temperature steam cleaners (minimum 170 $\mathrm{F} ; 10 \mathrm{~m}$ radius clean-up) should be used.

Vomiting episodes in public washrooms aerosolise the virus and flushing public commodes after diarrhea may aerosolise viral particles as well. Virus particles are shed in the stool for weeks, although the infectivity for the entire duration of shedding has yet to be defined. Since it is not practical to isolate someone beyond clinical symptoms for the duration of viral shedding, comprehensive education of the passenger or crew member on effective personal hygiene and hand washing is critical. Cultural variations in passengers and crew as to routine personal sanitation procedures can impact compliance with accepted public health standards. Proper hand washing is the only effective means of eliminating the virus $[3,4]$.

Another challenge with isolation is ensuring that any items in the isolated cabins are properly isolated and sanitised until the cabin can be sanitised post isolation. Cabin mates bringing items such as used dishes, magazines or video discs out of the cabin can spread the virus. Asymptomatic cabin mates do not have to be isolated; the quickest way to give someone Norovirus is to isolate them in the same cabin for 24-48 h. Instead, the cabin mate should be extensively educated on isolation procedures for their cabin mate, on rapid self-reporting if any symptoms develop and on meticulous personal hygiene and hand washing [4].

Because of negative ramifications, passenger non-compliance with self-reporting is always a challenge and any possible means of screening, surveillance, communication and education to identify every ill individual must be a part of any outbreak prevention plan. Even though most cruise lines now offer free medical visits in case of acute gastrointestinal symptoms and compensation for days in isolation, there are numerous obstacles to self-reporting. Passengers do not want to miss parts of their cruise, especially key ports they have specifically anticipated visiting. Websites have even warned passengers from reporting AGE symptoms and many bring medication with them 'just in case'. Hence, they tend to underreport, or lie, as in our case. Therefore, any means of identifying ill passengers for the protection of all on board is welcome and perseverance with identification of these individuals is critical.

Although used on many ships for years, the 'Cruise Vessel Security and Safety Act of 2010' (The Kerry-Matsui Law) ensures that security video cameras are installed in targeted areas on all cruise ships carrying American passengers to US ports [5]. At least 1 company has now instituted a policy 
that any and all public vomiting and faecal incidents are to be investigated via CCTV if the person is not immediately identified. As illustrated by our case, a tool designed for safety and security has now been enlisted into the outbreak prevention program.

\section{CONCLUSIONS}

In conclusion, all passenger ships visiting US ports now have surveillance video cameras, which can assist in finding and containing potential index cases for AGE outbreaks. Whether that action prevented an outbreak in our case, no one will ever know, but continuous and vigorous preventive efforts will over time reduce number and size of AGE outbreaks.

\section{REFERENCES}

1. US Centers for Disease Control and Prevention. Vessel Sanitation Program. Outbreak Updates for International Cruise Ships. http:// www.cdc.gov/nceh/vsp/surv/gilist.htm (accessed 09 February 2014).

2. US Centers for Disease Control and Prevention. Vessel Sanitation Program. About VSP. http://www.cdc.gov/nceh/vsp/desc/aboutvsp. htm (accessed 09 February 2014).

3. Mouchtouri VA, Nichols G, Rachiotis G et al. State of the art: public health and passenger ships. Int Marit Health 2010; 61: 49-98.

4. US Centers for Disease Control and Prevention. Vessel Sanitation Program. VSP 2011 Operations Manual. http://www.cdc.gov/nceh/vsp/ operationsmanual/opsmanual2011.pdf(accessed 09 February 2014).

5. One Hundred Eleventh Congress of the United States of America at the Second Session. The Cruise Vessel Security and Safety Act of 2010. http://www.uscg.mil/hq/cg2/cgis/CruiseVesselAct.asp (accessed 09 February 2014). 